\title{
Ptbamnce/Al as a High-Efficiency Catalyst for Nox Storage and Reduction as a Function of Cycling Conditions
}

\author{
Nguyen Le Phuc* \\ Catalysis Research Department, Vietnam Petroleum Institute, Vietnam
}

Submitted: November 08, 2017; Published: December 05, 2017

*Corresponding author: Nguyen Le Phuc, Catalysis Research Department, Vietnam Petroleum Institute, Lot E2b-5, D1 Road, Saigon Hi-Tech Park, Tan Phu Ward, Dist 9, Ho Chi Minh City 708400, Vietnam; Email: nguyenlp.pvpro@vpi.pvn.vn

\begin{abstract}
The aim of the study was to present novel PtBaMnCe/Al material as the high-efficiency catalyst for NOx storage and reduction (NSR) application. In the first part of this paper, the performance of PtBaMnCe/Al catalyst on the NOx conversion to $\mathrm{N}_{2}$ was presented. Compared with traditional model PtBa/Al catalyst, the PtBaMnCe/Al catalyst exhibit at least 2 times higher in NOx conversion efficiency at $400 \mathrm{oC}$. More interesting, ammonia yield on PtBaMnCe/Al is limited to a very lower level (nil). With $6 \% \mathrm{H}_{2}$ in the rich pulse, the $94 \%$ of NOx conversion to $\mathrm{N}_{2}$ can be obtained with PtBaMnCe/Al catalyst at $400 \mathrm{oC}$. The second part deals with sulfur resistance of PtBaMnCe/Al catalyst. Sulfur poisoning, regeneration of sulfated catalysts and NOx removal efficiency under rich/lean cycling conditions are studied. PtBaMnCe/Al is more sulfur resistant than PtBa/Al. However, the sulfur poisoning is irreversible and only $85 \%$ of the initial NOx conversion could be recovered after the regeneration treatment.
\end{abstract}

Keywords: Emission Control; Lean Burn; NOx Storage and Reduction; Sulfur in Fuel; Lean/rich cycle

\section{Introduction}

Lower $\mathrm{CO}_{2}$ emissions from automotive sources are necessary and lead to the development of diesel and lean-burn engines. However, exhaust gases from these engines contain NOx in excess of $\mathrm{O}_{2}$, which makes NOx reduction into $\mathrm{N}_{2}$ very difficult. One possible solution is the use of the NOx storage reduction (NSR) catalyst [ -3], working in transient periods: during the lean condition, NOx are firstly oxidized and stored as nitrites or nitrates on a basic material, usually barium oxide. Periodically, the catalyst is regenerated: the stored $\mathrm{NOx} \mathrm{NO}_{2}$ ) are reduced in $\mathrm{N}_{2}$ during a short excursion in rich condition. Nevertheless, the major drawback of this system is the deactivation of the catalyst, mainly due to sulfur poisoning [2,3], and ammonia emission can be formed during the short excursion under rich conditions, especially when hydrogen is used as reducer [-6].

In our previous study [5], ammonia intermediate pathway was clearly demonstrated for the reduction of the stored NOx with H2. It appears that, when hydrogen is missing in the rich pulses, that are fully converted, the ammonia selectivity tends to be nil because the produced NH3 can react with the remaining stored NOx. In opposition, if some hydrogen remains, the ammonia selectivity increases with the amount of excessive hydrogen. It induces that NOx reduction with $\mathrm{H}_{2}$ into ammonia is faster than the NOx selective catalytic reduction with ammonia. This is a fundamental result for our next step: catalyst modification for a better NOx conversion to $\mathrm{N}_{2}$.

In the first part of this paper, our latest result in catalyst improvement with a multi-component PtBaMnCe/Al sample will be presented. In the second part of this paper, the impact of sulfur in gasoline on the performance of NSR catalyst will be discussed. Sulfur poisoning, regeneration of sulfated catalysts and NOx removal efficiency under rich/lean cycling conditions are studied [7].

\section{Experimental}

\section{Catalyst preparation}

The detailed preparation protocols are reported in our previous studies [8]. The reference catalyst contains $1 \mathrm{wt} \% \mathrm{Pt}$ and $20 \mathrm{wt} \% \mathrm{BaO}$ supported on alumina. Alumina powder $(230$ $\mathrm{m}^{2}$.g-1) was immersed in an ammonia solution and was firstly impregnated using a barium nitrate salt. After evaporation at $80 \mathrm{oC}$ and drying at $120 \mathrm{oC}$, the obtained powder was treated at $700^{\circ} \mathrm{C}$ under synthetic dry air. Platinum was then impregnated using a Pt $\left(\mathrm{NH}_{3}\right)_{2}\left(\mathrm{NO}_{2}\right)_{2}$ aqueous solution. After drying, the catalyst was pre-treated at 700 oC for $4 \mathrm{~h}$ under $\mathrm{N}_{2}$, and finally 
stabilized at 700 oC for $4 \mathrm{~h}$ under a mixture containing $10 \% \mathrm{O}_{2}$, $5 \% \mathrm{H}_{2} \mathrm{O}$ in $\mathrm{N}_{2}$. The modified samples were prepared using the same protocol except that the nitrate salts of Mn(IV), and Ce (III) were simultaneously added with the barium salt. In this case, a part of alumina was replaced to assure the desired "additive/Ba" molar ratio. The catalysts containing both $\mathrm{Mn}$ and Ce were also prepared. In this case, $\mathrm{Mn} / \mathrm{Ba}$ and $\mathrm{Ce} / \mathrm{Ba}$ molar ratio are always 1. The Mn-Ce modified catalysts are noted PtBaMnCe/Al.

\section{Catalytic activity measurements: NOx conversion in cycling conditions}

Table 1: Rich and lean gas compositions used for the NOx conversion test (60s lean/3s rich). Total flow rate: $10 \mathrm{~L} . \mathrm{h}^{-1}$.

\begin{tabular}{|c|c|c|c|c|c|c|}
\hline Gas & NO & $\mathbf{H}_{2}$ & $\mathbf{O}_{2}$ & $\mathbf{C O}_{2}$ & $\mathbf{H}_{\mathbf{2}} \mathbf{O}$ & $\mathbf{N}_{\mathbf{2}}$ \\
\hline Rich & - & $3-6 \%$ & - & $10 \%$ & $10 \%$ & Balance \\
\hline Lean & $500 \mathrm{ppm}$ & - & $10 \%$ & $10 \%$ & $10 \%$ & Balance \\
\hline
\end{tabular}

Before measurement, the catalyst $(60 \mathrm{mg})$ was pre-treated in situ at $450 \mathrm{oC}$ under $3 \% \mathrm{H}_{2}, 10 \% \mathrm{H}_{2} \mathrm{O}, 10 \% \mathrm{CO}_{2}$ and $\mathrm{N}_{2}$ for $15 \mathrm{~min}$. The sample was then cooled down to $400 \mathrm{oC}$ under the same mixture. The NOx conversion was studied in cycling condition by alternatively switching between lean (60s) and rich (3s) conditions using electro-valves. The gas composition is described Table 2: NOx storage/reduction efficiency test at $400 \mathrm{oC}$ with $3 \% \mathrm{H}_{2}$
(Table 1). $\mathrm{NO}$ and $\mathrm{NO}_{2}$ were followed by chemiluminescence, $\mathrm{N}_{2} \mathrm{O}$ by specific FTIR, $\mathrm{H}_{2}$ by mass spectrometry. Before the analyzers, $\mathrm{H}_{2} \mathrm{O}$ was trapped in a condenser at $0 \mathrm{oC}$. The trapped water was analyzed by two different HPLCs for $\mathrm{NH}^{4+}, \mathrm{NO}_{2}-$ and $\mathrm{NO}^{3-}$. $\mathrm{NO}^{2-}$ and $\mathrm{NO}^{3-}$ were added to the unconverted NOx. The $\mathrm{N} 2$ selectivity is calculated assuming no other $\mathrm{N}$-compounds than $\mathrm{NO}, \mathrm{NO}_{2}, \mathrm{~N}_{2} \mathrm{O}$, $\mathrm{NH}_{3}$.

\section{Results and Discussions}

\section{NOx storage-reduction efficiency of PtBaMnCeX/Al catalyst}

The influence of cerium-manganese addition on the NOx storage-reduction efficiency of $\mathrm{PtBa} / \mathrm{Al}$ was studied at $400 \mathrm{oC}$ using first $3 \% \mathrm{H}_{2}$ in the rich pulses. For comparison, results obtained with the $\mathrm{PtBa} / \mathrm{Al}$ reference catalyst are also reported in (Figures 1 \& 2). At $400 \mathrm{oC}$ with $3 \% \mathrm{H}_{2}$ in the rich pulses, the hydrogen conversion reaches $100 \%$ with $\mathrm{PtBaMnCe} / \mathrm{Al}$ catalyst (Table 2). Hence, the NOx conversion could be limited by the reducer amount. However, the NOx conversion to $\mathrm{NH}_{3}$ over this sample is higher than $\mathrm{PtBa} / \mathrm{Al}$ catalylst. More interestingly, the ammonia selectivity becomes nil with $\mathrm{PtBaMnCe} / \mathrm{Al}$ catalyst.

\begin{tabular}{|c|c|c|c|c|c|c|c|c|}
\hline \multirow[b]{2}{*}{ Catalyst } & \multicolumn{4}{|c|}{$3 \% \mathrm{H}_{2}$ in the rich pulse } & \multicolumn{4}{|c|}{$6 \% \mathrm{H}_{2}$ in the rich pulse } \\
\hline & $\begin{array}{c}\mathrm{H}_{2} \\
\text { conversion } \\
(\%)\end{array}$ & $\begin{array}{c}\text { NOx } \\
\text { conversion } \\
(\%)\end{array}$ & $\begin{array}{c}\mathrm{N}_{2} \text { selectivity } \\
(\%)\end{array}$ & $\begin{array}{c}\mathrm{NH}_{3} \text { selectivity } \\
(\%)\end{array}$ & $\begin{array}{c}\mathbf{H}_{2} \\
\text { conversion }\end{array}$ & $\begin{array}{c}\text { NOx } \\
\text { conversion } \\
(\%)\end{array}$ & $\begin{array}{c}\mathrm{N}_{2} \text { selectivity } \\
(\%)\end{array}$ & $\begin{array}{c}\mathrm{NH}_{3} \text { selectivity } \\
(\%)\end{array}$ \\
\hline $\mathrm{PtBa} / \mathrm{Al}$ & 85 & 45 & 67 & 33 & 63 & 48 & 57 & 43 \\
\hline PtBaMnCe/Al & 100 & 70 & 100 & 0 & 99 & 94 & 100 & 0 \\
\hline
\end{tabular}

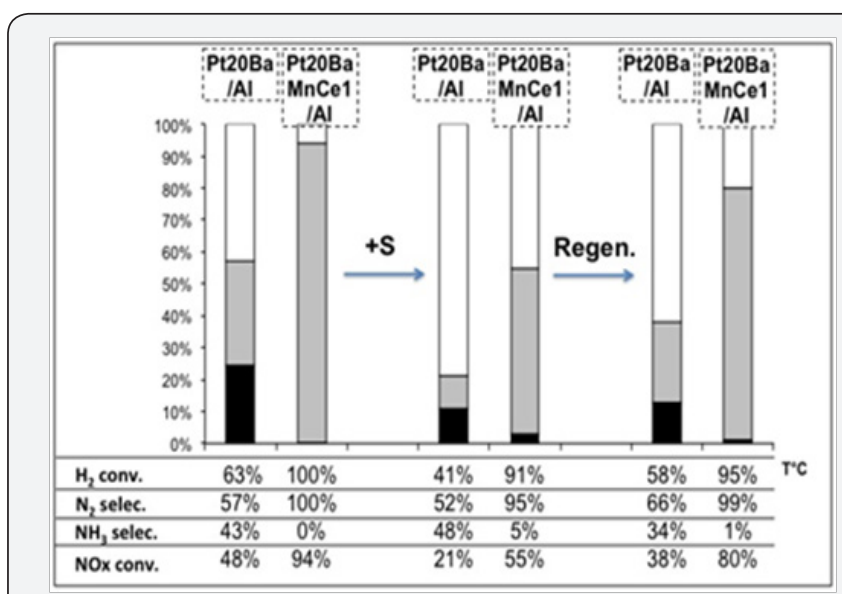

Figure 1: NOx storage/reduction efficiency of PtBa/Al and PtBaMnCe/Al catalysts, test at $400{ }^{\circ} \mathrm{C}$ with $6 \% \mathrm{H}_{2}$ (b) in the rich pulses. NOx conversion (\%) into $\mathrm{N}_{2}\left(\right.$ ) and into $\mathrm{NH}_{3}(\mathbf{m})$ : impact of sulfur poisoning and catalyst regeneration.

Thus, with this condition with full $\mathrm{H}_{2}$ conversion, the in situ formed ammonia is able to react with the remaining stored NOx to produce $\mathrm{N}_{2}$. With $6 \% \mathrm{H}_{2}$ in the rich pulses (Table 1), a significant NOx conversion improvement is observed with PtBaMnCe/ Al sample, from $70 \%$ to $94 \%$. These values can be considered as optimal values since the NOx storage rates of this sample reach $96 \%$ (result not shown). For the reference catalyst, the increase of $\mathrm{H}_{2}$ content in the rich pulse only leads to an increase in $\mathrm{NH}_{3}$ selectivity. This study shows that $\mathrm{PtBaMnCe} / \mathrm{Al}$ catalyst is very promising for NOx storage-reduction application. Most importantly, the NH3 yield is very low (nil) with this catalyst. Mn-Ce addition in NSR catalyst leads to the enhancement of the catalytic properties. It can be attributed to an improvement of the reaction between the ammonia formed in situ and the remaining stored NOx [6].

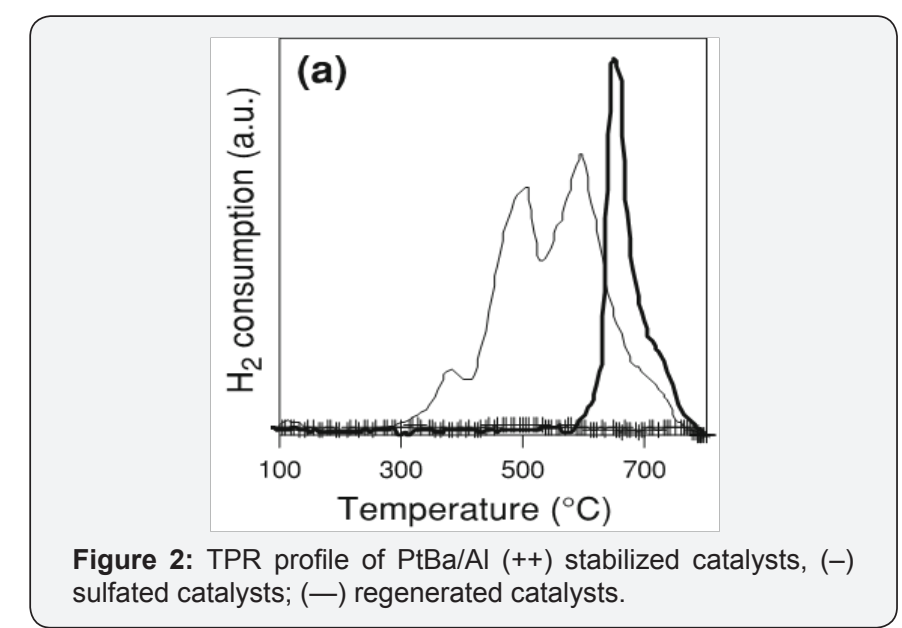




\section{Impact of sulfur in gasoline on the performance of model NSR catalyst}

In this section, the impact of sulfur on the performance of model NSR catalyst is focused. Firstly, the NSR catalyst was sulfated before catalytic activity measurement in order to simulate the deposition of sulfur compound in gasoline onto the catalyst surface. And then, the regeneration of sulfated catalyst was studied. The sulfating treatment was performed at $300 \mathrm{oC}$ with $\mathrm{SO}_{2}$ and corresponds to a $2.0 \mathrm{wt} \% \mathrm{~S}$ theoretical content if all the sulfur is stored on the catalyst. The regeneration of sulfated catalysts was carried out at 550 oC for $30 \mathrm{~min}$ under rich conditions with a mixture containing $2.5 \% \mathrm{H}_{2}, 10 \% \mathrm{CO}_{2}$, and $10 \% \mathrm{H}_{2} \mathrm{O}$ in $\mathrm{N}_{2}$.

\section{$\mathrm{SO}_{2}$ poisoning and regeneration}

The NOx conversion rate of the fresh, sulfated and after sulfur regeneration treatment of $\mathrm{Pt} 20 \mathrm{Ba} / \mathrm{Al}$ and Pt20BaMnCe1/ $\mathrm{Al}$ catalysts, measured at $400^{\circ} \mathrm{C}$, are reported in Figure 1 . After the sulfating treatment, the NOx storage-reduction capacities strongly decrease. For Pt20Ba/Al, a loss of $56 \%$ is observed. Mn-Ce doped sample is more resistant toward the poisoning treatment, with a loss of $41 \%$. After the regeneration treatment, only $79 \%$ of the initial value is recovered over Pt20Ba/Al, indicating that an efficient regeneration of the NOx storage sites cannot obtain. This rate is slightly higher for Pt20BaMnCe/Al $(85 \%)[9,10]$.

The sulfated Pt20Ba/Al catalyst was characterized by $\mathrm{H}_{2}-$ TPR (Figure 2). The sample was first in situ pretreated at 300 oC under pure oxygen. The reduction was carried out with $1 \%$ $\mathrm{H} 2$ from room temperature up to 800 oC. As described in [4], the TPR profile of the sulfated $\mathrm{Pt} / 10 \mathrm{Ba} / \mathrm{Al}$ catalyst exhibits two main peaks around 500 and $600 \mathrm{oC}$. The first one is attributed to the simultaneous reduction of aluminum sulfates and some well dispersed barium sulfates located in platinum proximity. The second peak, around $600 \mathrm{oC}$, is ascribed to the reduction of surface barium sulfates, and the observed shoulder near 750 oC corresponds to bulk barium sulfate reduction.

Assuming a $\mathrm{H}_{2} / \mathrm{SO}_{4}{ }^{2}$ - ratio of 4 for the sulfate reduction (X-SO4+4H2-->X-S + 4 $\mathrm{H}_{2} \mathrm{O}$ and/or X-SO $+4 \mathrm{H}_{2}-->\mathrm{X}-\mathrm{O}+\mathrm{H}_{2} \mathrm{~S}+3 \mathrm{H}_{2} \mathrm{O}$ ), total sulfur content can be deduced from hydrogen consumption. After the sulfur regeneration, only $58 \%$ of the deposited sulfur is removed. Moreover, a stabilization of the remaining sulfates is observed. This result indicates that the sulfur poisoning is irreversible. In addition to a possible incomplete surface cleaning, the reducing treatment can induce some structural changes in the doped catalysts. Indeed, a slight deactivation of the PtBaMnCe/Al catalyst was also observed after the sulfur regeneration treatment without previous sulfating procedure.

\section{Conclusion}

In the first part of this study, it was shown that $\mathrm{Ce}, \mathrm{Mn}$ addition to $\mathrm{PtBa} / \mathrm{Al}$ led to an improvement of the NOx reduction (conversion and selectivity). A near total NOx conversion to N2 can be observed at $400 \mathrm{oC}$ with PtBaMnCe/Al. In the second part, the effect of sulfur in the gasoline on the catalyst performance was observed. The sulfur resistance of PtBaMnCe/Al catalyst is higher than reference $\mathrm{PtBa} / \mathrm{Al}$ catalyst. Unfortunately, the NOx storage-reduction property cannot be fully recovered after the sulfur regeneration. These results clearly indicate that the lower sulfur level in fuels is indispensable for current and future emission control systems.

\section{References}

1. G Liu, PX Gao (2011) A review of NOx storage/reduction catalysts: mechanism, materials and degradation studies. Catalysis Science \& Technology (1): 552-568.

2. Epling WS (2004) Overview of the Fundamental Reactions and Degradation Mechanisms of NOx Storage/Reduction Catalysts. Catalysis Reviews 46(2): 163-245.

3. Beñat Pereda Ayo, M Unai De La Torre, Pilar González Marcos (2015) Influence of ceria loading on the NOx storage and reduction performance of model Pt-Ba/Al203 NSR catalyst. Catalysis Today (241): 133-142.

4. Sedlmair C (2002) Studies on the deactivation of NOx storage-reduction catalysts by sulfur dioxide. Catalysis Today 75(1-4): 413-419.

5. EC Corbos, Xavier Courtois, Nicolas Bion, Patrice Marecot, Daniel Duprez (2008) Impact of the support oxide and Ba loading on the sulfur resistance and regeneration of $\mathrm{Pt} / \mathrm{Ba} /$ support catalysts. Applied Catalysis B: Environmental 80(1-2): 62-71.

6. Clayton RD, Harold MP, Balakotaiah V (2008) NOx storage and reduction with $\mathrm{H}_{2}$ on $\mathrm{Pt} / \mathrm{BaO} / \mathrm{Al}_{2} \mathrm{O}_{3}$ monolith: Spatio-temporal resolution of product distribution. Applied Catalysis B: Environmental 84(3-4): 616630.

7. Lietti L, Nova I, Forzatti P (2008) Role of ammonia in the reduction by hydrogen of NOx stored over Pt-Ba/Al2O3 lean NOx trap catalysts. Journal of Catalysis 257(2): 270-282.

8. Liu Z, JA Anderson (2004) Influence of reductant on the thermal stability of stored NOx in $\mathrm{Pt} / \mathrm{Ba} / \mathrm{Al} 203$ NOx storage and reduction traps. Journal of Catalysis 224(1): 18-27.

9. Le Phuc $\mathrm{N}$ (2011) A study of the ammonia selectivity on $\mathrm{Pt} / \mathrm{BaO} / \mathrm{Al}_{2} \mathrm{O}_{3}$ model catalyst during the NOx storage and reduction process. Catalysis Today 176(1): 424-428.

10. Le Phuc N (2009) NOx storage and reduction properties of Pt/CexZr1$\mathrm{xO}_{2}$ mixed oxides: Sulfur resistance and regeneration, and ammonia formation. Applied Catalysis B Environmental 93: 12-21. 


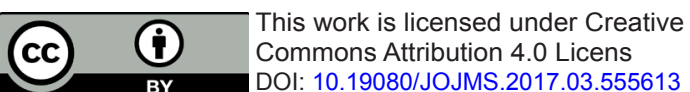
BY DOI: 10.19080/JOJMS.2017.03.555613

\section{Your next submission with Juniper Publishers} will reach you the below assets

- Quality Editorial service

- Swift Peer Review

- Reprints availability

- E-prints Service

- Manuscript Podcast for convenient understanding

- Global attainment for your research

- Manuscript accessibility in different formats ( Pdf, E-pub, Full Text, Audio)

- Unceasing customer service

Track the below URL for one-step submission https://juniperpublishers.com/online-submission.php 